\title{
Application of Thermal Kinetics to Small Carbon Ion Clusters
}

\author{
Chava Lifshitz ${ }^{*}$ and Pablo Sandler \\ Department of Physical Chemistry and The Fritz Haber Research Center for Molecular Dynamics, \\ The Hebrew University of Jerusalem, Jerusalem 91904, Israel
}

Hans-Friedrich Grützmacher and Jing Sun

Fakultät für Chemie, Universităt Bielefeld, D-4800 Bielefeld, Germany

Thomas Weiske and Helmut Schwarz

Institut für Organische Chemie der Technischen Universität Berlin, W-1000 Berlin 12, Germany

Received: January 26, 1993; In Final Form: March 24, 1993

\begin{abstract}
Kinetic energy release distributions (KERDs) were obtained experimentally for unimolecular decomposition of small carbon ion clusters $\mathrm{C}_{n}{ }^{+}, n=10-13$ and 18 , made by dissociative ionization from perchloro conjugated hydrocarbons. A model-free approach due to Klots, based on the application of thermal kinetics to small systems, allowed the extraction of binding energies for these clusters. The results were found to be in very good agreement with literature values for collisionally activated dissociation (CAD) threshold energies. The ion $\mathrm{C}_{11}{ }^{+}$ demonstrates a particularly high binding energy in agreement with its magic character in $\mathrm{C}_{n}{ }^{+}$mass spectra, while $\mathrm{C}_{13}{ }^{+}$has a relatively low binding energy, reflected in its low abundance in such spectra.
\end{abstract}

\section{Introduction}

Carbon cluster ions $\mathrm{C}_{n}{ }^{+}$have been investigated extensively in recent years because of their probable important role in interstellar chemistry ${ }^{1}$ and combustion processes. ${ }^{2}$ The investigation of carbon cluster ions promises to shed light on chemical processes occurring in the universe. 3,4

Carbon cluster ions have been prepared in the laboratory by direct laser vaporization of a graphite rod., ${ }^{3,5}$ This enables one to make cluster ions with various sizes and to study their unimolecular and bimolecular reactions, metastable fractions, and kinetic energy releases. $3,6-9$ Under special conditions, even macroscopic quantities of $\mathrm{C}_{60}$ are generated. ${ }^{10}$ Carbon ion clusters can also be made by dissociative electron impact ionization. The size of the clusters formed in early studies" was limited to about $n=6$. However, perchloro conjugated hydrocarbons do yield considerable amounts of $\mathrm{C}_{n}{ }^{+}$ions by exhaustive chlorine elimination following electron impact ionization. ${ }^{12} \mathrm{C}_{n}{ }^{+}$ions with $n=3,5-7$, $10-12,14$ and 16 were made by dissociative electron ionization from highly unsaturated perchloro compounds, ${ }^{13-15}$ and their properties were studied by tandem (MS/MS) mass spectrometry.

The properties of the two groups of $\mathrm{C}_{n}{ }^{+}$clusters - those made by laser vaporization of graphite and the ones made by dissociative electron ionization-were found to be remarkably similar, suggesting similar structures, irrespective of the mode of production.

Several profound changes were noted for $\mathrm{C}_{n}{ }^{+}$ions with $n$ between 9 and 11: There is a leveling off in the unimolecular reactivity and in the second ionization energy; 15 there is a characteristic change from $\mathrm{C}_{3}$ to $\mathrm{C}_{1}$ loss for unimolecular MIKES (mass-analyzed ion kinetic energy spectroscopy).6,15 These and other data on photodissociation spectra ${ }^{16}$ and ion/molecule reactions ${ }^{17}$ indicated a change in structure from linear for $n=$ 3-9 to cyclic for $n \geq 10$. These assumptions were verified by the more recent elegant ion mobility studies. ${ }^{18}$ These studies demonstrated for $n=3-6$ a single isomer, probably linear, for $n=7-10$ two isomers, most likely linear and cyclic, and for $n=$ 11-20 again single isomers, whose mobilities correlate to the mobilities of the cyclic forms of $n=7-10$.

- Archie and Marjorie Sherman Professor of Chemistry.
In the present study, we concentrated on deriving binding energies from kinetic energy release distributions (KERDs) for some of the cyclic ions $\mathrm{C}_{n}{ }^{+}$with $11 \leq n \leq 18$ made by dissociative ionization from perchlorinated polyaromatic compounds (PPAs) and for $\mathrm{C}_{10}{ }^{+}$. Binding energies have recently been determined ${ }^{19}$ by collisionally activated dissociation (CAD) for $2 \leq n \leq 15$. Previous photodissociation results ${ }^{16}$ were found to be misleading. ${ }^{19}$ Relatively high CAD threshold energies $(\sim 7.5-8.0 \mathrm{eV})$ were observed for $\mathrm{C}_{11}{ }^{+}$and $\mathrm{C}_{12}{ }^{+}$, as compared to other small carbon ion clusters.

Binding energies may be deduced from KERDs, by applying phase space theory (PST). ${ }^{3}$ This has required modeling which in turn necessitates assumptions concerning the structures of the ions, their total internal energies, and properties of the transition states (vibrational frequencies, rotational constants, etc.). This has been done for $\mathrm{C}_{n}^{+}$with $5 \leq n \leq 11$. While modeling may be done in an internally consistent manner, ${ }^{3}$ a model-free approach may be applied. Such a theoretical approach has been developed by Klots ${ }^{20}$ and has been applied in the present study. The results will be compared with previous ones from CAD thresholds ${ }^{19}$ and KERD/PST studies ${ }^{3}$ where available.

\section{Experimental Section}

PPAs were prepared from the appropriate polycyclic aromatic hydrocarbons (PAHs) by perchlorination with the BMC reagent ${ }^{21}$ consisting of a mixture of $\mathrm{S}_{2} \mathrm{Cl}_{2}, \mathrm{AlCl}_{3}$, and $\mathrm{SO}_{2} \mathrm{Cl}_{2}$ and heated to $64^{\circ} \mathrm{C}$ for $4 \mathrm{~h}$. At the end of the reactions, the mixture was treated with ice-water. The product was filtered and purified by recrystallization or column chromatography on silica gel. The yields of the perchlorinated product were generally ca. $45 \%$. The perchlorinated hydrocarbons obtained usually decompose when heated to more than $150^{\circ} \mathrm{C}$. Their identification was achieved by $70-\mathrm{eV}$ electron mass spectra and ${ }^{13} \mathrm{C}$ NMR spectra. The precursors for $\mathrm{C}_{10}{ }^{+}, \mathrm{C}_{11}{ }^{+}, \mathrm{C}_{12}{ }^{+}, \mathrm{C}_{13}{ }^{+}$, and $\mathrm{C}_{18}{ }^{+}$were compounds I-V, respectively. Perchloromethylnaphthalene (II), perchloroacenaphthacene (III), and perchlorofluorene (IV) demonstrate relatively large $\mathrm{C}_{n}{ }^{+}$signals (ca. 10\%). Other precursors were prepared for $\mathrm{C}_{14}{ }^{+}$and $\mathrm{C}_{16}{ }^{+}$(VI, VII), but the $\mathrm{C}_{n}{ }^{+}$signals were small or could not be resolved from ion impurities, to obtain meaningful metastable peak shapes. 
<smiles>ClC1=C(Cl)C(Cl)(Cl)c2cc(Cl)ccc2C1(Cl)Cl</smiles><smiles>CC(C)(C)c1c(Cl)c(Cl)c2cc(Cl)ccc2c1Cl</smiles>

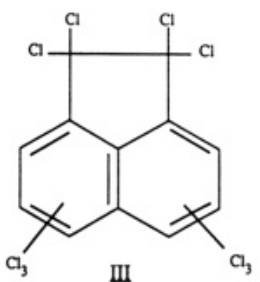<smiles>Clc1cccc2c1C(Cl)(Cl)c1ccccc1-2</smiles>

IV<smiles>ClC1=C(Cl)C(Cl)(Cl)c2c(c3ccccc3c3cc(Cl)ccc23)C1(Cl)Cl</smiles>

$\underline{v}$<smiles>ClC1C=CC2C3C=CC(Cl)(Cl)C3c3ccccc3C(Cl)(Cl)C(Cl)(Cl)C2C1</smiles>

VI

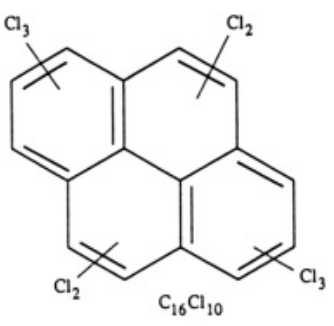

VII
Metastable ion peak shapes were measured for MIKES scans. The experiments were performed with a substantially modified ZAB-HF mass spectrometer which has been described in detail previously. ${ }^{22}$ (See Figure 1.) The facility is a four-sector mass spectrometer with BEBE configuration where B denotes a magnetic and $\mathrm{E}$ an electric sector. The desired cluster ion is mass selected by the first double-focusing BE mass spectrometer, at relatively high mass resolution to avoid chlorine-containing interference peaks. Its identity is established through its unimolecular and collisionally activated (CA) reactions taking place in the third field free region by performing a scan of B2 and detecting ions at D3 (see Figure 1). Once the identity and the purity of the cluster have been established, it is transmitted through B2. The electrostatic analyzer E2 is scanned in the desired voltage region appropriate for the unimolecular decomposition of the cluster in the fourth field free region. The products of this reaction are detected at D4.

The samples were introduced via the solids inlet probe. The following ion source conditions were employed: ion source temperature $200^{\circ} \mathrm{C}$; ion trap current $200 \mu \mathrm{A}$; acceleration voltage $8 \mathrm{kV}$; mass resolution $m / \Delta m \geq 2000$ (10\% valley definition).

The energy resolution $E / \Delta E$ (fwhh) of the parent cluster ions measured behind E2 was 850 , and behind $E 1$ it was 4000 . Ten to 40 single spectra have been accumulated for each profile by scanning E2. Data were acquired by the AMD DP10 data system.

\section{Results and Discussion}

The MIKE spectra obtained for $\mathrm{C}_{10}{ }^{+}-\mathrm{C}_{14}{ }^{+}$and $\mathrm{C}_{18}{ }^{+}$from PPAs (Table I) are almost identical in every respect, in terms of neutral fragments lost and branching ratios, with the ones reported for laser ablation of graphite. ${ }^{6}$ The CA spectra are much more complex, demonstrating all possible $\mathrm{C}_{n}{ }^{+}$daughter ions from a certain precursor. Similar results were reported previously ${ }^{15}$ from

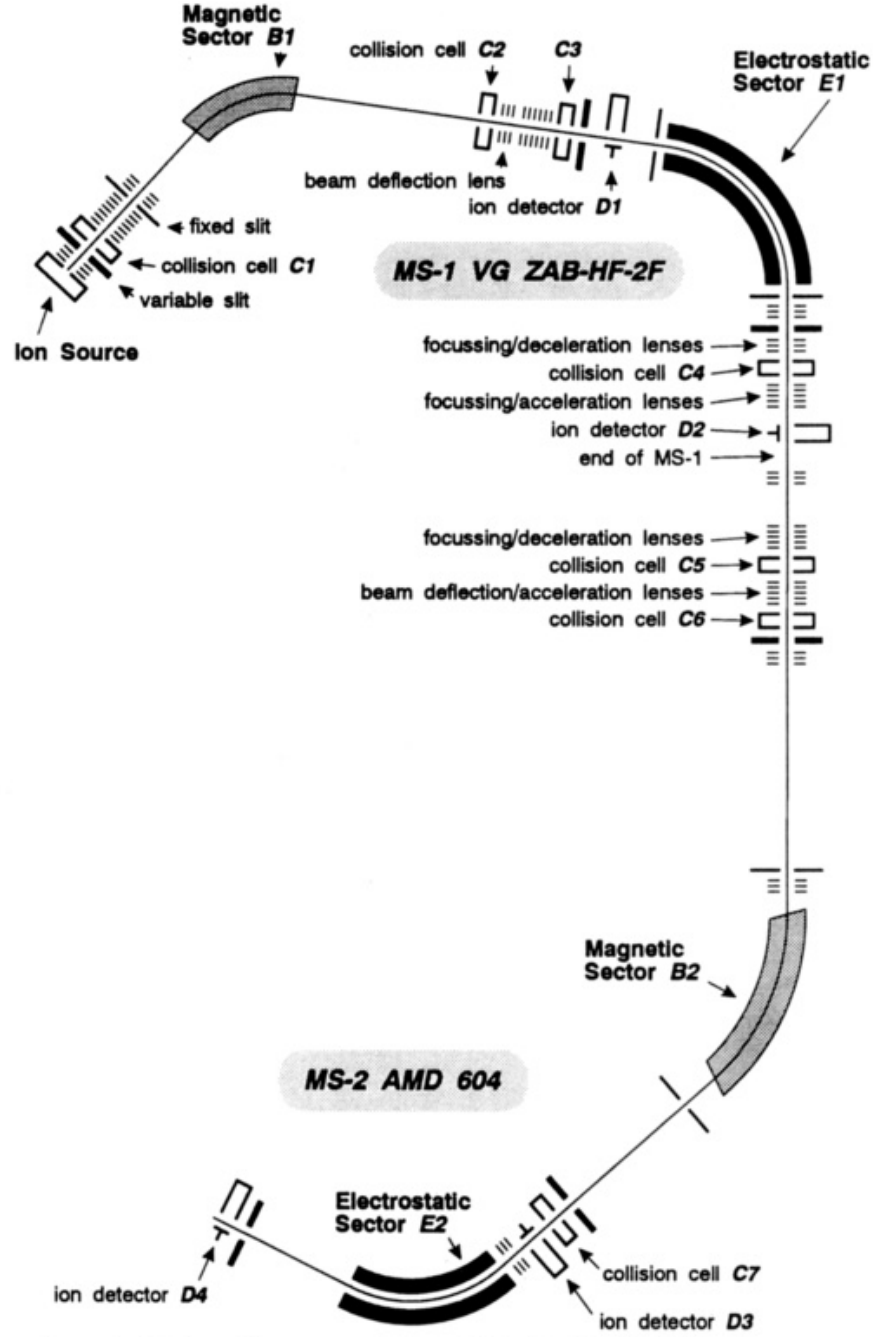

Figure 1. Schematic representation of the Berlin BEBE tandem mass spectrometer (see text and ref 22 for details).

TABLE I: Branching Ratios for the Neutral Lost in Unimolecular MIKES of $\mathrm{C}_{n}^{+}$Ions

\begin{tabular}{cccr}
\hline \multirow{2}{*}{$\begin{array}{c}\text { cluster } \\
\text { ion size }\end{array}$} & 1 & 2 & \multicolumn{3}{c}{ neutral lost size } \\
\cline { 2 - 4 } 10 & & & 100 \\
11 & 100 & 5 & 9 \\
12 & 100 & & 3 \\
13 & & & 100 \\
14 & & & 100 \\
18 & & & 100
\end{tabular}

different PPAs, indicating that successive chlorine losses cause a complete loss of memory of the original structure leading to identical-most stable-ion structures for $\mathrm{C}_{n}{ }^{+}$formed from exhaustive chlorine eliminations as by laser ablation of graphite. The present results are more accurate in some instances. For example, $\mathrm{C}_{3}$ elimination from $\mathrm{C}_{11}{ }^{+}$was observed only under collisional activation in the previous study employing $\mathrm{C}_{n} \mathrm{Cl}_{n}$ precursors, ${ }^{15}$ while presently we observe the unimolecular lowabundance $\mathrm{C}_{3}$ loss channel in $\mathrm{C}_{11}{ }^{+}$as well as the $\mathrm{C}_{3}$ and $\mathrm{C}_{2}$ losses from $\mathrm{C}_{12}{ }^{+}$, in agreement with the laser ablation study. ${ }^{6}$ The MIKE spectrum for $\mathrm{C}_{11}{ }^{+}$is shown in Figure 2. The CA spectra for $\mathrm{C}_{n}^{+}, n=10-14,16$, and 18, are shown in Figure 3.

The KERDs were determined from the first derivatives of the metastable-ion peak shapes ${ }^{23-25}$ with deconvolution of the main beam distribution. Metastable peak shapes were pseudoGaussian; the one for the reaction

$$
\mathrm{C}_{11}^{+} \rightarrow \mathrm{C}_{10}^{+}+\mathrm{C}_{1}
$$

is reproduced in Figure 4. The KERDs obtained are Boltzmann- 


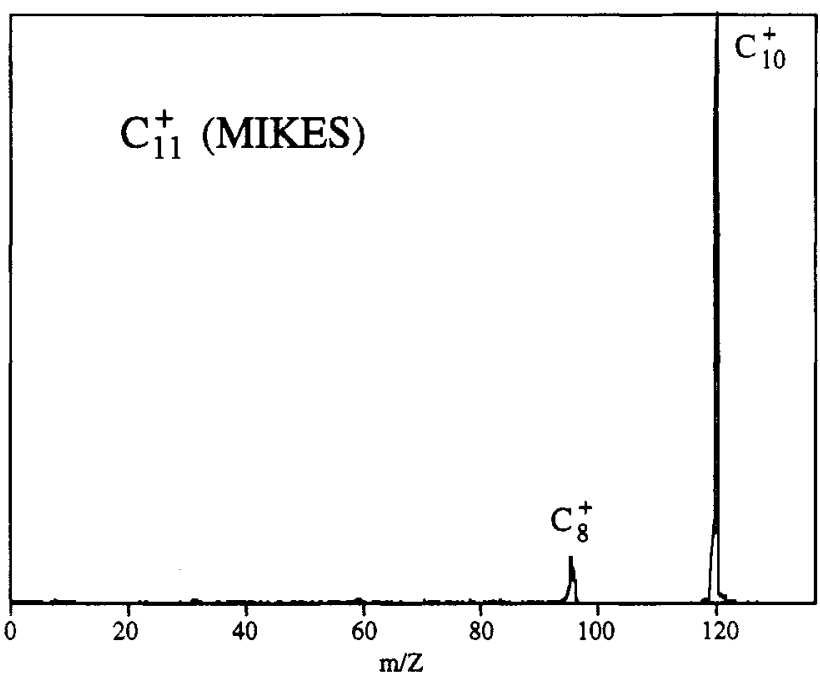

Figure 2. Typical metastable MIKE scan for $\mathrm{C}_{11}{ }^{+}$. The ion $\mathrm{C}_{11}{ }^{+}$is mass selected by the first $B E$ mass spectrometer, $B 1 E 1$; it is transmitted through B2, and E2 is scanned. The electrostatic analyzer voltage of E2 was converted to the appropriate $\mathrm{m} / \mathrm{z}$ scale.
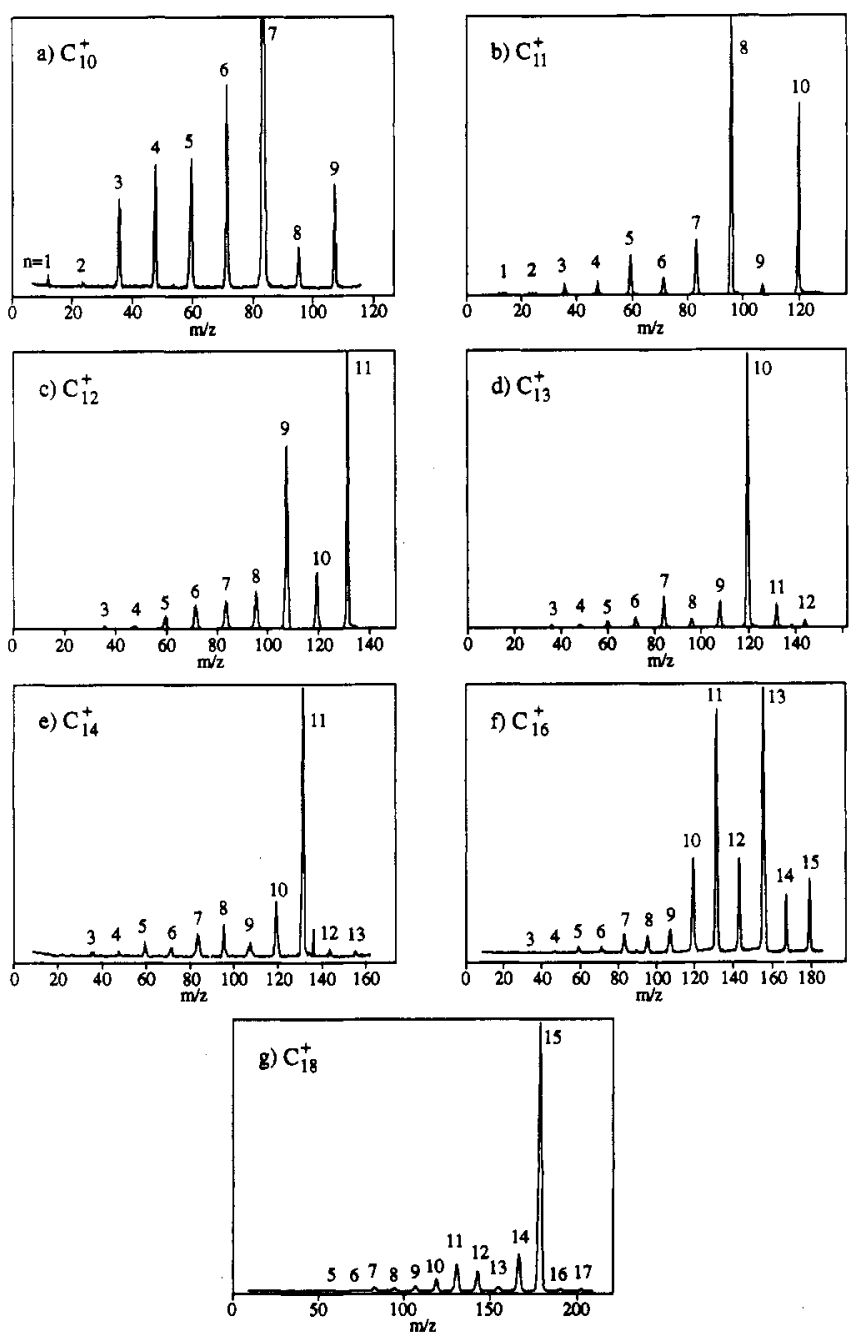

Figure 3. Collisionally activated dissociation spectra for the cluster ions indicated. Precursor ions are mass selected by B1E1, they are collisionally activated in the third field free region, a scan of B2 is performed, and the product ions of the CADs are detected at D3.

like. An example of the KERD for reaction 1 is shown in Figure 5 . The average kinetic energy releases, $\langle\epsilon\rangle$, determined in the present study, are summarized in Table II and compared with previous laser ablation data and with previous data from dissociative ionization of PPAs $\left(\mathrm{C}_{n} \mathrm{Cl}_{m}\right)$, where these are available.

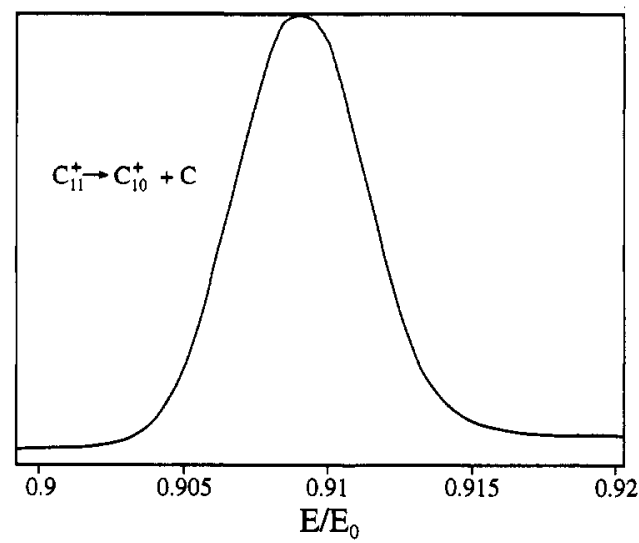

Figure 4. Laboratory kinetic energy peak shape. The metastable $\mathrm{C}_{10^{+}}$ product peak from reaction 1 is shown.

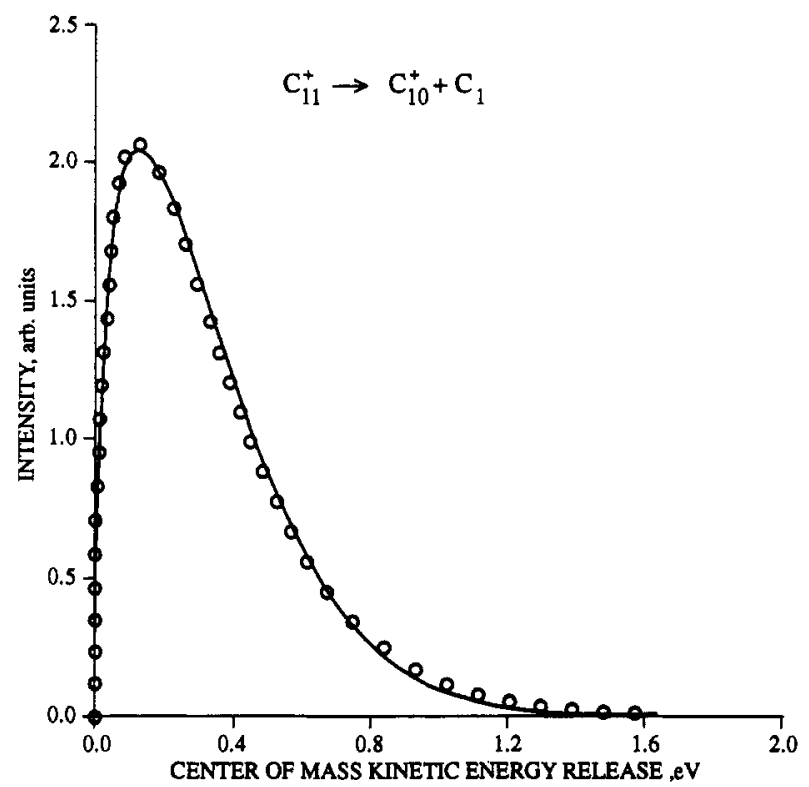

Figure 5. Center of mass kinetic energy release distribution for reaction 1. A differentiation of the laboratory kinetic energy distribution (Figure 4) and transformation to center-of-mass energy scale yields the solid line. The model-free thermal kinetics calculation (eq 2) is given by the open circles.

TABLE II: Average Kinetic Energy Release, $\langle\epsilon\rangle$, for Mestastable Fragmentation Reactions

\begin{tabular}{|c|c|c|c|}
\hline \multirow[b]{3}{*}{ reaction } & \multicolumn{3}{|c|}{$\langle\epsilon\rangle, \mathrm{eV}$} \\
\hline & \multicolumn{2}{|c|}{ dissociative ionization of $\mathrm{C}_{n} \mathrm{Cl}_{m}$} & \multirow{2}{*}{$\begin{array}{l}\text { laser ablation } \\
\text { of graphite }\end{array}$} \\
\hline & present results & lit. results ${ }^{14}$ & \\
\hline $\begin{array}{l}\mathrm{C}_{10^{+}} \rightarrow \mathrm{C}_{7}^{+}+\mathrm{C}_{3} \\
\mathrm{C}_{11}{ }^{+} \rightarrow \mathrm{C}_{10^{+}}+\mathrm{C}_{1} \\
\mathrm{C}_{11^{+}} \rightarrow \mathrm{C}_{8}^{+}+\mathrm{C}_{3} \\
\mathrm{C}_{12}{ }^{+} \rightarrow \mathrm{C}_{11}^{+}+\mathrm{C}_{1} \\
\mathrm{C}_{12}{ }^{+} \rightarrow \mathrm{C}_{10^{+}}+\mathrm{C}_{2} \\
\mathrm{C}_{12}{ }^{+} \rightarrow \mathrm{C}_{9}^{+}+\mathrm{C}_{3} \\
\mathrm{C}_{13}{ }^{+} \rightarrow \mathrm{C}_{10^{+}}+\mathrm{C}_{3} \\
\mathrm{C}_{18}{ }^{+} \rightarrow \mathrm{C}_{15^{+}}+\mathrm{C}_{3}\end{array}$ & $\begin{array}{l}0.238 \pm 0.03 \\
0.338 \pm 0.03 \\
0.46 \pm 0.05 \\
0.308 \pm 0.03 \\
0.29 \pm 0.03 \\
0.54 \geq 0.05 \\
0.274 \pm 0.03 \\
0.426 \pm 0.04\end{array}$ & $0.256 \pm 0.055$ & $\begin{array}{l}0.254 \pm 0.026 \\
0.335 \pm 0.025 \\
0.267 \pm 0.032\end{array}$ \\
\hline
\end{tabular}

The unimolecular decompositions of $\mathrm{C}_{n}{ }^{+}$ions may be viewed as evaporations from small particles. This process has been treated theoretically by Klots. ${ }^{26}$ It has been proposed that the average kinetic energy with which a monomeric unit leaves the surface of an aggregate can measure the temperature of the transition state, $T^{*}$. This assumption holds, provided the decomposition reaction does not demonstrate a reverse activation energy. The pseudo-Gaussian metastable peaks obtained for all the present $\mathrm{C}_{n}{ }^{+}$decompositions ( $\equiv$ evaporations) demonstrate the absence of reverse activation energies. This idea was developed further ${ }^{20,26 \mathrm{~d}, \mathrm{~g}}$ by Klots, treating the full KERDs. Thermal kinetics was applied 


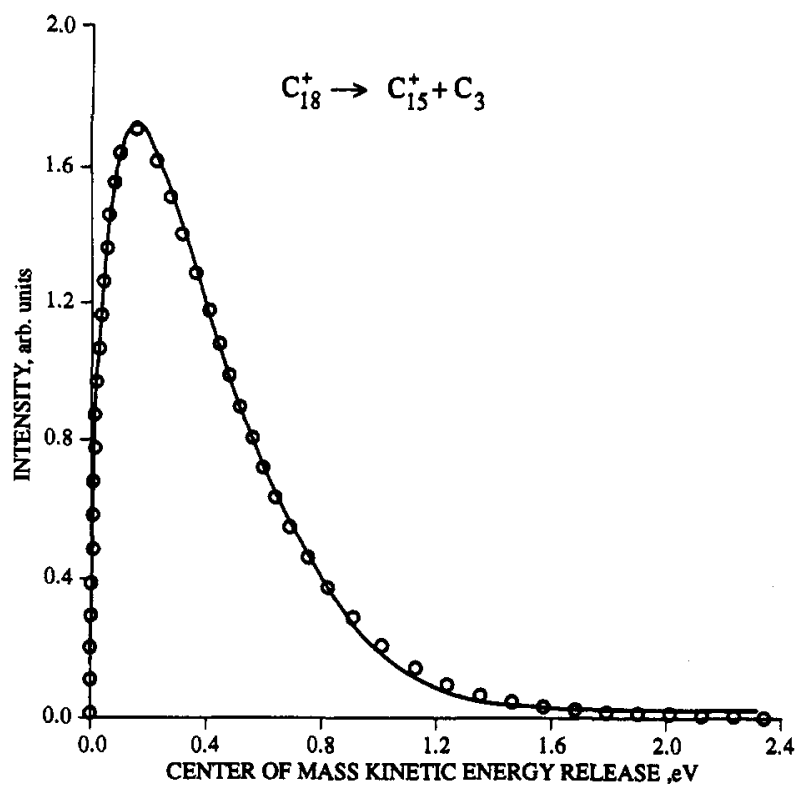

Figure 6. Center-of-mass KERD for reaction 3. See caption to Figure 5.

in two stages: (i) an idealized model-free approach;20,26d (ii) a model in which the interaction between the separating fragments is a function of their radial separation. ${ }^{26 \mathrm{~g}}$ In the model-free approach, the KERD is written in the form

$$
p(\epsilon) \approx \epsilon^{l} \exp \left(-\epsilon / k_{\mathrm{B}} T^{*}\right) \quad 0 \leq l \leq 1
$$

where $\epsilon$ is the kinetic energy and $k_{\mathrm{B}}$ is Boltzmann's constant. The KERDs for all of the reactions of Table II could be fitted with expression 2. Examples of the fits are shown for reaction 1 and for

$$
\mathrm{C}_{18}{ }^{+} \rightarrow \mathrm{C}_{15}{ }^{+}+\mathrm{C}_{3}
$$

in Figures 5 and 6, respectively. The parameters $/$ were all between 0 and 1 as required; the values observed were in fact $0.4 \leq l \leq$ 0.6 . It can be very easily shown that eq 2 leads to

$$
\left.k_{\mathrm{B}} T^{*}=\overline{\left(\epsilon^{2}\right.}-\overline{\epsilon^{2}}\right) / \bar{\epsilon}
$$

Thus, a measurement of the first two moments of a KERD can yield the temperature $T^{*}$. This approach has been applied previously ${ }^{20}$ to the evaporation of $\mathrm{C}_{2}$ from $\mathrm{C}_{60}{ }^{+}$. However, $\epsilon$ and $\epsilon^{2}$ have to be known very accurately. ${ }^{27}$ Experimental errors will almost invariably cause the second moment to be overestimated. ${ }^{28}$ That is one of the reasons for applying a model in which one treats the interaction between the separating fragments as a radial potential. ${ }^{268.28}$ Furthermore, eq 2 is the thermodynamic limit for a potential of the form $V=-\zeta / r^{N}$ with $N \geq 2$, appropriate when the rotational temperature is equilibrated with the other temperatures. Equation 2 can be explicitly derived in a number of cases and is believed never to be badly wrong. When one ionizes $\mathrm{C}_{60}$ and $\mathrm{C}_{70}$ directly as we have done recently, ${ }^{28,29}$ this is not strictly applicable, since the angular momenta of the $\mathrm{C}_{60}{ }^{+}$and $\mathrm{C}_{70}+$ formed are very low and the rotational temperature is much less than that of the other degrees of freedom. In the present study, these two problems have been avoided: (a) We have fitted the experimental KERDs with eq 2 directly, as explained above, and extracted $T^{*}$ and $l$, circumventing the necessity to use eq $4 .{ }^{28}$ (b) The $\mathrm{C}_{n}{ }^{+}$ion evaporations studied here follow a long series of consecutive unimolecular chlorine decompositions, ensuring equilibration of the rotational temperature with the other degrees of freedom. In fact, one prior dissociation suffices to equilibrate the rotational temperature. ${ }^{28,30}$ Equation 2 is therefore applicable.

The transition-state temperatures extracted from the KERDs are summarized in Table III. These temperatures are employed
TABLE III: Parameters Obtained in This Study for $\mathrm{C}_{\mathbf{}^{+}}^{+}$ Reactions

\begin{tabular}{lccc}
\multicolumn{1}{c}{ reaction } & $T^{*}, \mathrm{~K}$ & $T_{\mathrm{b}, \mathrm{K}}$ & $\begin{array}{c}\text { binding energy, } \\
\mathrm{eV}\end{array}$ \\
\hline $\mathrm{C}_{10^{+}} \rightarrow \mathrm{C}_{7}++\mathrm{C}_{3}$ & $1740 \pm 100$ & $3030 \pm 180$ & $6.1 \pm 0.4$ \\
$\mathrm{C}_{11^{+}} \rightarrow \mathrm{C}_{10^{+}}+\mathrm{C}_{1}$ & $2580 \pm 100$ & $4200 \pm 170$ & $8.5 \pm 0.4$ \\
$\mathrm{C}_{11^{+}} \rightarrow \mathrm{C}_{8}+\mathrm{C}_{3}$ & $3130 \pm 300$ & $5090 \pm 500$ & $(10.3 \pm 1.0)^{a}$ \\
$\mathrm{C}_{12^{+}} \rightarrow \mathrm{C}_{11^{+}+\mathrm{C}_{1}}$ & $2300 \pm 100$ & $3550 \pm 160$ & $7.2 \pm 0.3$ \\
$\mathrm{C}_{12^{+}} \rightarrow \mathrm{C}_{10^{+}}+\mathrm{C}_{2}$ & $2210 \pm 100$ & $3400 \pm 160$ & $6.9 \pm 0.3$ \\
$\mathrm{C}_{12^{+}} \rightarrow \mathrm{C}_{9}++\mathrm{C}_{3}$ & $3340 \pm 300$ & $5150 \pm 500$ & $(10.4 \pm 1.0)^{a}$ \\
$\mathrm{C}_{13^{+}} \rightarrow \mathrm{C}_{10^{+}}+\mathrm{C}_{3}$ & $2000 \pm 100$ & $2950 \pm 150$ & $6.0 \pm 0.3$ \\
$\mathrm{C}_{18^{+}} \rightarrow \mathrm{C}_{15^{+}}+\mathrm{C}_{3}$ & $3120 \pm 200$ & $4050 \pm 260$ & $8.2 \pm 0.5$ \\
\multicolumn{4}{l}{ These binding energies are suspect; see text. }
\end{tabular}

to extract the binding energies of the cluster ions, in two steps: (1) to calculate a bath temperature, $T_{b} ;(2)$ to calculate an evaporation energy $\Delta E_{\text {vap }}$, from $T_{\mathrm{b}}$, which is equated with the binding energy.

$T_{\mathrm{b}}$ is defined by Klots ${ }^{20,26 \mathrm{~d}}$ as the isokinetic temperature to which a heat bath must be set to yield a thermal rate constant $k\left(T_{\mathrm{b}}\right)$ equal to the microcanonical rate coefficient, $k(E)$,

$$
k(E)=k\left(T_{\mathrm{b}}\right)
$$

where $E$ is the well-defined energy of the reactant cluster ion. The equivalent bath temperature is given by a relation,

$$
T_{\mathrm{b}}=\Delta E_{\text {vap }} / \gamma k_{\mathrm{B}}
$$

reminiscent of Trouton's rule. The parameter $\gamma$ is the Gspann parameter. It is a universal parameter, independent of cluster type or size. Clusters evaporating on a time scale of roughly 10 $\mu \mathrm{s}$, which is the characteristic time scale in sector mass spectrometers, have energies such that if eq 5 is obeyed, then $\gamma$ is found semiempirically to be equal to $23.5 \pm 1.5 .^{20.32}$ The transition-state temperature associated with such energies, which satisfy eq 5 , is ${ }^{20,32}$

$$
T^{*}=T_{\mathrm{b}} \frac{\gamma / C}{\exp (\gamma / C)-1}
$$

where $C$ is the heat capacity (in units of $k_{\mathrm{B}}$ ) of the cluster (at $T_{\mathrm{b}}$ ) minus one. The heat capacity may be estimated or may be calculated from known vibrational frequencies. In view of the high bath temperatures, the heat capacities were taken at their semiclassical limits $C=3 n-7$.

The $T_{\mathrm{b}}$ 's were calculated from the experimentally derived $T^{*}$ 's using eq 7. They are included in Table III. Finally, the binding energies (or evaporation energies, $\Delta E_{\text {vap }}$ ) were calculated using eq 6, and the results are also included in Table III.

The results obtained in the present study for the carbon ion binding energies are compared with the dissociation thresholds from the CAD experiment ${ }^{19}$ in Figure 7 . A clear correlation in terms of the local maximum for $n=11$ and the local minimum for $n=13$ is observed between the two studies. The CAD experiments measured the dominant channel under their conditions which was $C_{3}$ loss. Figure 7 contains our data for the dominant loss under MIKES, which for $\mathrm{C}_{11}{ }^{+}$and $\mathrm{C}_{12}{ }^{+}$is $\mathrm{C}_{1}$ loss. Table III shows that the binding energies deduced for $C_{3}$ loss from $\mathrm{C}_{11}{ }^{+}$and $\mathrm{C}_{12}{ }^{+}$are considerably higher than for the parallel channels. The possibility of artifacts like contributions from collision-induced dissociations in these two reactions cannot be excluded. These two reactions are minor channels. Some indication for broadening is seen by comparison of the $\langle\epsilon\rangle$ data for

$$
\mathrm{C}_{11}{ }^{+} \rightarrow \mathrm{C}_{8}{ }^{+}+\mathrm{C}_{3}
$$

from laser ablation experiments ${ }^{3}$ and the present results (Table II). While the agreement between the two sets of data for reaction 1 is excellent, it is rather poor for reaction 8.

Previously determined binding energies from KERDs ${ }^{3}$ do not demonstrate the sharp rise between $\mathrm{C}_{10}{ }^{+}$and $\mathrm{C}_{11}{ }^{+}$observed in 


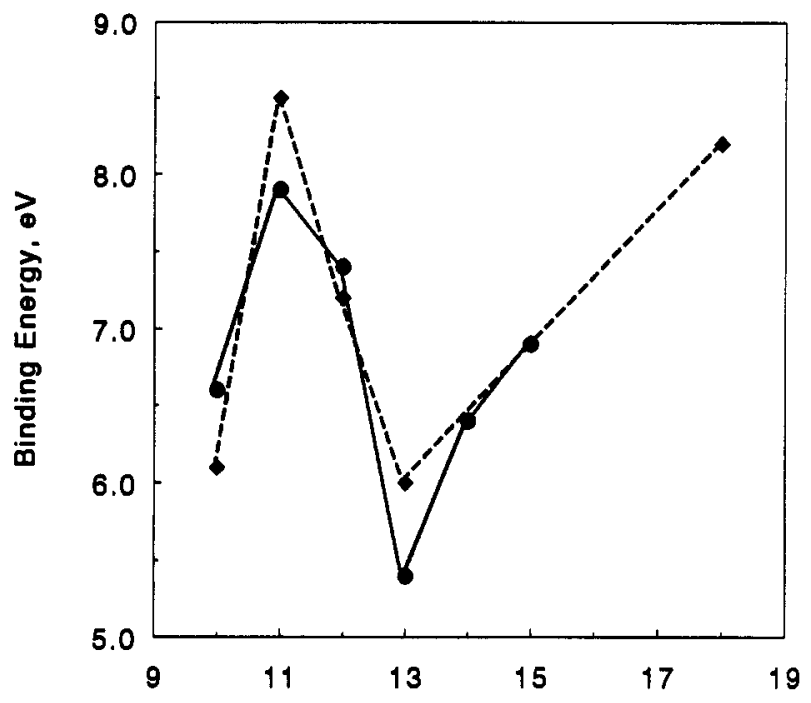

Number of Atoms in Cluster

Figure 7. Comparison of binding energies deduced in the present study (४) with CAD thresholds from ref $19(0)$. The points for $n=13$ and 18 of the present study were connected to lead the eye; intermediate binding energies were not measured.

the present study and under CAD. ${ }^{19}$ This rise has tentatively been ascribed to the structural change from linear to cyclic. ${ }^{19}$ $\mathrm{C}_{10}{ }^{+}$is known to exist in two isomeric structures, linear and cyclic ${ }^{18}$; however, the cyclic structure, while being more stable than the linear one, ${ }^{33}$ may still be quite strained. ${ }^{19}$ The strain is lifted in $\mathrm{C}_{11}{ }^{+}$and $\mathrm{C}_{12}{ }^{+}$, causing high binding energies. On the one hand, cyclic $\mathrm{C}_{10}{ }^{+}$can be formed from $\mathrm{C}_{11}{ }^{+}$but the neutral coproduct $C_{1}$ is much less stable than $C_{3}$; on the other hand, for $C_{3}$ neutral to be formed, the ionic product is most probably linear $\mathrm{C}_{8}{ }^{+}$, which requires the two consecutive bond cleavages of the $\mathrm{C}_{11}{ }^{+}$ring. Only for $\mathrm{C}_{13}{ }^{+}$is $\mathrm{C}_{3}$ loss possible together with a fairly stable $\mathrm{C}_{10}{ }^{+}$ (ring?) coproduct.

We can test our derived binding energies for internal consistency. The heats of formation of $C_{1}$ and $C_{2}$ are known: ${ }^{34}$ $\Delta H_{\text {fo }}\left(\mathrm{C}_{1}\right)=170.0 \mathrm{kcal} / \mathrm{mol} ; \Delta H_{\text {fo }}\left(\mathrm{C}_{2}\right)=196.8 \mathrm{kcal} / \mathrm{mol}$. If one combines reaction 1 , whose $\Delta H_{1}=8.5 \pm 0.4 \mathrm{eV}$, with

$$
\mathrm{C}_{12}{ }^{+} \rightarrow \mathrm{C}_{11}{ }^{+}+\mathrm{C}_{1}
$$

whose $\Delta H_{9}=7.2 \pm 0.3 \mathrm{eV}$, then we get

$$
\mathrm{C}_{12}{ }^{+} \rightarrow \mathrm{C}_{10}{ }^{+}+2 \mathrm{C} \quad \Delta H_{10}=15.7 \pm 0.7 \mathrm{eV}
$$

On the other hand,

$$
\mathrm{C}_{12}{ }^{+} \rightarrow \mathrm{C}_{10}{ }^{+}+\mathrm{C}_{2} \quad \Delta H_{11}=6.9 \pm 0.3 \mathrm{eV}
$$

The difference between $\Delta H_{10}$ and $\Delta H_{11}$ is $8.8 \pm 1 \mathrm{eV}$, which is not consistent with

$$
\mathrm{C}_{2} \rightarrow 2 \mathrm{C} \quad \Delta H_{12}=6.21 \mathrm{eV}
$$

This may indicate that the error limits stated should be broader or the $\mathrm{C}_{10}{ }^{+}$formed via eq 10 is internally excited or a different isomer than the one formed via eq 11 .

We have estimated the error limit without taking into account the range of values possible for $\gamma$. The "best value" for the Gspann parameter reported, ${ }^{31} \gamma=23.5 \pm 1.5$, was obtained from the decay of metastable populations of copper, xenon, argon, and sodium clusters; even clusters with as few as 10 atoms were described quite well. Two factors may be important concerning the application of $\gamma=23.5$ in the present study: (1) The carbon ion clusters are valence clusters; i.e., they have covalent bonds. Do they undergo evaporations in the same sense as argon clusters? (2) The value of $\gamma=23.5$ is appropriate for the most probable evaporation rate constant $k_{0}=10^{5} \mathrm{~s}^{-1}$. However, the most probable rate constant in the fourth field free region of the BEBE instrument employed, appropriate for $\mathrm{C}_{n}{ }^{+}$with $n=10-18$, is $k$ $\approx(2.1-1.5) \times 10^{4} \mathrm{~s}^{-1}$. The appropriateness of $\gamma=23.5$ for carbon ion cluster decompositions has been tested recently ${ }^{35}$ for the $\mathrm{C}_{60}{ }^{+}$ dissociation. This was done using the Arrhenius equation

$$
k\left(T_{\mathrm{b}}\right)=A \exp \left(-\Delta E_{\mathrm{vap}} / k_{\mathrm{B}} T_{\mathrm{b}}\right)
$$

and the relation

$$
A=\sigma e\left(k_{\mathrm{B}} T_{\mathrm{b}} / h\right) \exp \left(\Delta S^{*} / k_{\mathrm{B}}\right)
$$

where $\sigma$ is the reaction degeneracy, $h$ is Planck's constant, $\Delta S^{*}$ is the activation entropy, and

$$
\ln A-\ln k\left(T_{\mathrm{b}}\right)=\gamma
$$

The value of $\gamma$ was calculated from the two RRKM models adopted by $Y_{00}$ et al., ${ }^{36}$ to fit their photoionization data for $\mathrm{C}_{2}$ evaporation from $\mathrm{C}_{60}{ }^{+}$. The value obtained, ${ }^{35} \gamma=23.5 \pm 0.5$, is in excellent agreement with the semiempirical Gspann parameter for other cluster systems. ${ }^{31}$

The value of $\gamma$ may similarly be calculated for reaction 1 from the models adopted by Radi et al. ${ }^{3}$ These authors applied the transition-state switching (TSS) form of the phase space theory to analyze their data. Two sets of parameters were employed (Table X, ref 3)-for a tight transition state (TTS), which is rate determining, and for an orbiting transition state (OTS), which effects the kinetic energy release distribution. We calculated the activation entropies for these two transition states, ${ }^{37}$ the preexponential $A$ factors appropriate for $T_{\mathrm{b}}=4200 \mathrm{~K}$ (see Table III), and the parameter $\gamma$, using eqs 14 and 15 . The OTS has a $\gamma \approx$ 29 and is not relevant from our point of view. The TTS, which is rate determining, is the one appropriate for $k\left(T_{\mathrm{b}}\right)$. The $A$ factor calculated for the TTS is $A=2.9 \times 10^{14} \mathrm{~s}^{-1}$. The most probable rate constant in the fourth field region for $\mathrm{C}_{11}{ }^{+}$is $k=$ $2 \times 10^{4} \mathrm{~s}^{-1}$. These two values give through eq $15 \gamma=23.4$. This is in excellent agreement with the best value for $\gamma .{ }^{31}$ The value of $\gamma$ is clearly related to the degree of looseness of the transition state. The original model employed ${ }^{3}$ for reaction 1 assumed a linear $\mathrm{C}_{11}{ }^{+}$forming linear $\mathrm{C}_{10}{ }^{+}$, although the possibility of a cyclic $\mathrm{C}_{11}{ }^{+}$reactant was not excluded. The ion mobility experiments clearly indicate ${ }^{18}$ that $\mathrm{C}_{11}{ }^{+}$has to be cyclic. Production of $\mathrm{C}_{10}{ }^{+}$may be a two-step process: ring opening followed by $\mathrm{C}_{1}$ evaporation from linear $\mathrm{C}_{11}{ }^{+}$. The second step could correspond to a rather loose transition state in case linear $\mathrm{C}_{10}{ }^{+}$is formed or a fairly tight one if $\mathrm{C}_{1}$ is eliminated in a concerted fashion with $\mathrm{C}_{10}{ }^{+}$ring closure. These are still open questions, which may be studied by ab initio calculations, now in progress. ${ }^{33}$

The error bars on the binding energies (Table III) rise from $4-7 \%$ to $14-16 \%$ when the possible range of values $\gamma=23.5 \pm$ 1.5 is allowed for the Gspann parameter. The difference between $\Delta H_{10}$ and $\Delta H_{11}$ becomes consistent with $\Delta H_{12}$ for these broader error limits. Furthermore, it is plausible that the binding energy for $\mathrm{C}_{1}$ in $\mathrm{C}_{12}{ }^{+}$is lower then that for $\mathrm{C}_{2}$, since $\mathrm{C}_{1}$ loss from $\mathrm{C}_{12}{ }^{+}$ is the dominant channel (Table I).

There is a rise in the binding energy between $\mathrm{C}_{13}{ }^{+}$and $\mathrm{C}_{18}{ }^{+}$ (Figure 7). This may reflect the special stability of $\mathrm{C}_{18}$, which has been generated as a neutral, ${ }^{38}$ having two perpendicular systems of $\pi$ orbitals, with $4 n+2 \pi$ electrons each.

The special stability which we observe for $\mathrm{C}_{11}+$ (see Figure 7) is reflected in the fact that $n=11$ is a "magic" number for carbon ion cluster mass spectra, obtained under a variety of conditions: 39 It is invariably a very intense ion in the spectrum. At the same time, $\mathrm{C}_{13}+$ invariably demonstrates a very low abundance, ${ }^{39}$ which reflects its relatively low binding energy (Figure 7). The magic character of $\mathrm{C}_{11}{ }^{+}$and "antimagic" character of $\mathrm{C}_{13}{ }^{+}$are also reflected in a relatively low metastable fraction for $\mathrm{C}_{11}{ }^{+}$and relatively high metastable fraction for $\mathrm{C}_{13}{ }^{+}$, under unimolecular decay. ${ }^{3,7}$ Similarly under $\mathrm{CAD}$ in the present study, $\mathrm{C}_{11}{ }^{+}$ demonstrates a pronounced abundance while $\mathrm{C}_{13}{ }^{+}$has a rather 
low abundance for $\mathrm{CAD}$ of $\mathrm{C}_{18}+$ (Figure $3 \mathrm{~g}$ ). The same holds for $C A D$ of $\mathrm{C}_{16}{ }^{+}-\mathrm{C}_{11}{ }^{+}$is very intense; $\mathrm{C}_{13}{ }^{+}$is also intense in that spectrum (Figure $3 f$ ) but that reflects the special stability of $C_{3}$ neutral, which is the coproduct. $n=15$ and 19 are also magic numbers. ${ }^{39}$ We were unable, however, to determine binding energies for $\mathrm{C}_{16}{ }^{+}$and $\mathrm{C}_{17}{ }^{+}$or for $n \geq 19$, because of the lack of appropriate $\mathrm{C}_{n} \mathrm{Cl}_{m}$ precursors, giving high enough $\mathrm{C}_{n}{ }^{+}$abundances in their spectra. The special stability of $\mathrm{C}_{11}{ }^{+}, \mathrm{C}_{15}{ }^{+}$, and $\mathrm{C}_{19}{ }^{+}$ may be due to electronic structure-these should be aromatic rings. Similarly, $\mathrm{C}_{13}+$ is unstable since it is antiaromatic, having $4 n \pi$ electrons.

Acknowledgment. This research was supported by a grant from GIF, the German-Israeli Foundation for Scientific Research and Development. C.L. and H.S. thank the von Humboldt Foundation for the donation of the Max Planck Research Award, which helped to finance this research. H.S. is grateful to the Deutsche Forschungsgemeinschaft and the Fonds der Chemischen Industrie for financial support. We thank C. E. Klots and S. L. Anderson for very helpful comments.

\section{References and Notes}

(1) (a) Shiff, H. I.; Bohme, D. K. Astrophys. J. 1979, 232, 740. (b) Kroto, H. W.; Heath, J. R.; O'Brian, S. C.; Curl, R. F.; Smalley, R. E. Nature 1985, 318, 162. (c) Kroto, H. W.; McKay, K. Nature 1988, 331, 328.

(2) Zhang, Q. L.; O'Brien, S. C.; Heath, J. R.; Liu, Y.; Curl, R. F.; Kroto, H. W.; Smalley, R. E. J. Phys. Chem. 1986, 90, 525.

(3) Radi, P. P.; Rincon, M. E.; Hsu, M.-T.; Brodbelt-Lustig, J.; Kemper, P.; Bowers, M. T. J. Phys. Chem. 1989, 93, 6187.

(4) Cox, D. M.; Reichmann, K. C.; Kaldor, A. J. Chem. Phys. 1988, 88, 1588.

(5) McElvany, S. W.; Nelson, H. H.; Baronavski, A. P.; Watson, C. H.; Eyler, J. R. Chem. Phys. Lett. 1987, 134, 214.

(6) Radi, P. P.; Bunn, T. L.; Kemper, P. R.; Molchan, M. E.; Bowers,

M. T. J. Chem. Phys. 1988, 88, 2809.

(7) Radi, P. P.; Hsu, M.-T.; Brodbelt-Lustig, J.; Rincon, M.; Bowers, M. T. J. Chem. Phys. 1990, 92, 4817. 6934.

(8) Bowers, M. T.; Radi, P. P.; Hsu, M.-T. J. Chem. Phys. 1991, 94,

(9) Radi, P. P.; Hsu, M.-T.; Rincon, M. E.; Kemper, P. R.; Bowers, M. T. Chem. Phys. Lett. 1990, 174, 223.

(10) Krătschmer, W.; Lamb, L. D.; Fostiropoulos, K.; Hoffman, D. R. Nature 1990, 347, 354.

(11) Bohme, D. K.; Wlodek, S.; Williams, L.; Forte, L.; Fox, A. J. Chem. Phys. 1987, 87, 6934 .

(12) (a) Agranat, I.; Loewenstein, R. M.; Bergmann, E. D. Org. Mass Spectrom. 1971, 5, 289. (b) Schafer, L. Chem. Commun. 1968, 1622.

(13) Lifshitz, C., Iraqi, M. In The Structure of Small Molecules and Ions; Naaman, R., Vager, Z., Eds.; Plenum: New York, 1988; p 251.

(14) Lifshitz, C.; Peres, T.; Kababia, S.; Agranat, I. Int.J. Mass Spectrom. Ion Processes 1988, 82, 193.
(15) Lifshitz, C.; Peres, T.; Agranat, I. Int. J. Mass Spectrom. Ion Processes $1989,93,149$.

(16) Geusic, M. E.; Jarrold, M. F.; Mcllrath, T. J.; Freeman, R. R.; Brown, W. L. J. Chem. Phys. 1987, 86, 3862.

(17) (a) McElvany, S. W.; Dunlap, B. I.; O'Keefe, A. J. Chem. Phys. 1987, 86, 715. (b) McElvany, S. W. J. Chem. Phys. 1988, 89, 2063. (c) Parent, D. C.; McElvany, S. W. J. Am. Chem. Soc. 1989, 111, 2393.

(18) von Helden, G.; Hsu, M.-T.; Kemper, P. R.; Bowers, M. T. J. Chem. Phys. 1991, 95, 3835. 4719

(19) Sowa, M. B.; Hintz, P. A.; Anderson, S. L. J. Chem. Phys. 1991, 95,

(20) Klots, C. E. Z. Phys. D 1991, 2l, 335.

(21) (a) Ballester, M.; Molinet, C.; Castañer, J. J. Am. Chem. Soc. 1960, 82, 4254. (b) Ballester, M. Adv. Phys. Org. Chem. 1989, 25, 267.

(22) (a) Srinivas, R.; Sũlzle, D.; Weiske, T.; Schwarz, H. Int. J. Mass Spectrom. Ion Processes 1991, 107, 369. (b) Srinivas, R.; Sülzle, D.; Koch, W.; DePuy, C. H.; Schwarz, H. J. Am. Chem. Soc. 1991, 113,5970 . (c) Srinivas, R.; Bøhme, D. K.; Sülzle, D.; Schwarz, H. J. Phys. Chem. 1991, 95, 9836.

(23) Holmes, J. L.; Osborne, A. D. Int. J. Mass Spectrom. Ion Phys. 1977, $23,189$. 181 .

(24) Lifshitz, C.; Tzidony, E. Int. J. Mass Spectrom. Ion Phys. 1981, 39,

(25) Jarrold, M. F.; Wagner-Redeker, W.; Illies, A. J.; Kirchner, N. J.; Bowers, M. T. Int. J. Mass Spectrom. Ion Processes 1984, 58, 63.

(26) Klots, C. E. (a) J. Chem. Phys. 1985, 83, 5854; (b) Z. Phys. D 1987, 5, 83; (c) J. Phys. Chem. 1988, 92, 5864; (d) Z. Phys. D 1991, 20, 105; (e) Acc. Chem. Res. 1988, 21, 16 ; (f) Nature 1987, 327, 222: (g) Unimolecular Decomposition in a Spherically Symmetric Potential. J. Chem. Phys. Submitted.

(27) Lifshitz, C.; Iraqi, M.; Peres, T.; Fischer, J. E. Int.J. Mass Spectrom. Ion Processes 1991, 107, 565.

(28) Sandler, P.; Lifshitz, C.; Klots, C. E. Chem. Phys. Lett. 1992, 220 ,

(29) Sandler, P.; Peres, T.; Weissman, G.; Lifshitz, C. Ber. Bunsenges. Phys. Chem. 1992, 96, 1195.

(30) (a) Klots, C. E. Z. Naturforsch. 1972, 27a, 553. (b) Stace, A. J. J. Chem. Phys. 1990, 93, 6502.

(31) Klots, C. E. Int. J. Mass Spectrom. Ion Processes 1990, 100, 457.

(32) Lifshitz, C. Unimolecular and Collision Induced Decompositions of Selected Cluster Ions. Curr. Top. Ion Chem. Phys., in press.

(33) van Koppen, P. Personal communication, Nov 1992.

(34) Lias, S. G.; Bartmess, J. E.; Liebman, J. F.; Holmes, J. L.; Levin, R. D.; Mallard, W. G. J. Phys. Chem. Ref. Data 1988, 17, Supplement 1.

(35) Lifshitz, C.; Gotkis, Y.; Sandler P.; Laskin, J. Chem. Phys. Lett. 1992, 200, 406

(36) Yoo, R. K.; Ruscic, B.; Berkowitz, J. J. Chem. Phys. 1992, 96, 911.

(37) There is a typographical error ${ }^{33}$ in Table $X$ of ref 3 . The orbiting TS has only 25 vibrational degrees of freedom. Instead of two vibrations of $550 \mathrm{~cm}^{-1}$, there is only one $550-\mathrm{cm}^{-1}$ vibration.

(38) Diederich, F.; Rubin, Y.; Knobler, C. B.; Whetten, R. L.; Schriver, K. E.; Houk, K. N.; Li, Y. Science 1989, 245, 1088

(39) (a) McElvany, S. W.; Ross, M. M.; Callahan, J. H. Acc. Chem. Res. 1992, 25, 162. (b) Swalley, R. E. Acc. Chem. Res. 1992, 25, 98. (c) Gaber H.; Hiss, R.; Busmann, H.-G.; Hertel, I. V. Z. Phys. D 1992, 24, 307. (d) Doyle, R. J., Jr.; Ross, M. M. J. Phys. Chem. 1991, 95, 4954. 